\title{
QUAIS OS ENCAMINHAMENTOS METODOLÓGICOS/CURRICULARES PARA O PROCESSO DE FORMAÇÃO DE PROFESSORES, ENVOLVENDO O TRABALHO COM GÊNEROS MULTISSEMIÓTICOS OU PARA O USO DE TECNOLOGIAS EM SALA DE AULA? UMA REVISÃO
}

\author{
WHAT ARE THE METHODOLOGICAL/CURRICULAR FORWARDING FOR THE \\ TEACHER EDUCATION PROCESS, INVOLVING WORK WITH \\ MULTISEMIOTIC GENRES OR FOR THE USE OF TECHNOLOGIES IN THE \\ CLASSROOM? A REVIEW
}

Leila Cristina Arantes ${ }^{1}$ Islane Cristina Martins ${ }^{2}$

RESUMO: Introdução: A formação de professores se constitui numa prática que deve ser ressignificada constantemente, uma vez que o professor está sempre enfrentando novos desafios no seu métier. Um exemplo disso consiste no ensino mediado por tecnologias e no trabalho em sala de aula com gêneros multissemíoticos que circulam socialmente. Diante disso, é crucial que durante o seu processo de formação ele seja capacitado para o uso de tecnologias digitais e para o trabalho com gêneros discursivos multissemióticos/multimodais. Objetivo: Realizar uma revisão integrativa da literatura a fim de compreender quais são os encaminhamentos metodológicos/curriculares para o processo de formação de professores, envolvendo o trabalho com gêneros multissemióticos ou para o uso de tecnologias em sala de aula. Materiais e Métodos: Foi feita uma busca das referências nas bases Periódicos CAPES, Google Scholar em agosto de 2021. A busca permitiu a identificação de o8 artigos que se adequaram aos critérios estabelecidos. Resultados: A partir da análise dos dados foi possível verificar que as pesquisas realizadas constaram a deficiência dos cursos de formação de professores no que tange à preparação dos futuros discentes para o uso das tecnologias digitais e o trabalho com gêneros multissemitóticos em sala de aula, sendo que $25 \%$ dos artigos constaram a necessidade de se propor situações didáticas envolvendo o trabalho com produção de textos multissemióticos, outros $25 \%$ constaram a necessidade de aprimoramento ou revisão das matrizes curriculares dos cursos de formação de professores, $\mathrm{I2,5} \%$ relataram o crescimento da inquietação em se trabalhar com textos cujos meios são digitais, $12,5 \%$ constataram a necessidade de se repensar a formação docente para as questões emergentes da inserção das tecnologias da informação e comunicação como material didático pedagógico, $12 \%$ constatou que a formação docente deve garantir a articulação entre a teoria e prática e o

${ }^{I}$ Especialista em Ciências Criminais na Atualidade - PUC/MG. Email: leilaarantesı6@gmail.com ORCID: oooo-002-4840-8828

2 Doutora em Neurociências pela Universidade Federal de Pernambuco-UFPE. 
encaminhamento de atividades de cunho reflexivo e 12,5 \% concluíram que após uma teorização de professores com seus colegas, eles demonstram ter um certo letramento digital. Conclusão: Portanto, foi possível concluir que os encaminhamentos metodológicos/curriculares para o processo de formação de professores, envolvendo o trabalho com gêneros multissemióticos ou para o uso de tecnologias em sala de aula são: redefinição das matrizes curriculares dos cursos de formação de professores com inclusão de componentes curriculares que preparem os futuros docentes para o uso das tecnologias e o trabalho com gêneros multissemióticos em sala de aula, promoção de espaços para a reflexão sobre a prática de produção de textos multissemióticos durante o percurso de formação de professores, proporcionar aos futuros docentes experiências com o uso de tecnologias e o trabalho com gêneros multissemióticos em sala de aula durante o processo formativo, proposição de situações didáticas, envolvendo atividades de produção de textos por parte dos licenciandos

Palavras-chave: Formação de professores. Multissemiose. Tecnologias Digitais da Comunicação de Informação.

ABSTRACT: Introduction: Teacher education constitutes a practice that must be ever re-signified, since the teacher is always facing new challenges in his profession. An example of this is technology-mediated teaching and classroom work with socially circulating multisemiotic genres. Thus, it is crucial that during his training process he is trained to use digital technologies and to work with multisemiotic/multimodal discursive genres. Objective: Carrying out an integrative literature review in order to understand the methodological/curricular forwarding for the teacher education process, involving work with multisemiotic genres or for the use of technologies in the classroom. Materials and Methods: It was made a search of the references in the CAPES Periodicals, Google Scholar databases in August 2021. The search allowed the identification of 08 papers that met the established criteria. Results: From the data analysis, it was possible to analyze that the researches carried out showed the lack of the teacher education courses regarding the training of future students for the use of digital technologies and the work with multisemitotic genres in the classroom, wherein $25 \%$ of the papers found the need to propose didactic situations involving work with the production of multisemiotic texts, another $25 \%$ found the need to improve or revise the curricular matrices of teacher training courses, $12.5 \%$ reported the growing restlessness in if working with texts whose media are digital, $12.5 \%$ found the need to rethink teacher training for issues emerging from the insertion of information and communication technologies as pedagogical teaching material, $12 \%$ found that teacher training should ensure articulation between theory and practice and the forwarding of reflective activities and $12.5 \%$ concluded that after teachers theorize with their peers, they demonstrate to have a certain digital literacy. Conclusion: Hence, it was possible to conclude that the methodological/curricular forwarding for the teacher education process, involving work with multisemiotic genres or for the use of technologies in the classroom are: redefining the curricular matrices of teacher education courses with the inclusion of curricular components that prepare future teachers for the use of technologies and work with multisemiotic genres in the classroom, promoting of spaces for reflection on the practice of producing 
multisemiotic texts during the course of teacher education, provide future teachers with experiences with the use of technologies and work with multisemiotic genres in the classroom during the education process, proposition of didactic situations, involving text production activities by the undergraduate students.

Keywords: Teacher training. Multisemiosis. Digital Technologies of Information Communication.

\section{INTRODUÇÃO}

O universo educacional, dado o impacto das novas tecnologias, corresponde hoje à uma busca urgente por outros meios de ensinar e de aprender, seja quanto às novas formas de leitura e da escrita seja quanto aos diversos modos de usar a fala.

Dessa forma, com o acesso às diversas ferramentas tecnológicas disponíveis, não cabe mais à escola e aos professores se valerem de práticas pedagógicas estabelecidas a partir de matrizes curriculares tradicionais de ensino (DE OLIVEIRA; COSTA, 2017).

Além disso, os documentos oficiais assinalam as competências discursivas, como se observa do texto preliminar da Base Comum Curricular (BNCC), os quais apontam outras formas de ver o tratamento do ensino de língua portuguesa na escola (DE OLIVEIRA; COSTA, 2017).

Não só isso, as atividades do nosso cotidiano estão intimamente ligadas às práticas de letramentos digitais, ou seja, ao uso de dispositivos móveis com acesso à internet, seja para solucionar obrigações, realizar pesquisas, fazer compras, dentre outros (DE OLIVEIRA; COSTA, 2017).

A saber, letramentos digitais são "habilidades individuais e sociais necessárias para interpretar, administrar, compartilhar e criar sentido eficazmente no âmbito crescente dos canais de comunicação digital" (DUDENEY; HOCKLY; PEGRUM, 2016, p.17).

Com isso, diante do agir em sociedades multiletradas, necessário se faz avançar nas práticas de ensino desde as séries iniciais da educação básica ao ensino superior (DE OLIVEIRA; COSTA, 2017).

Desse modo, diante das orientações apresentadas pelos Parâmetros Curriculares, se tornou premente que a escola capacite seus alunos, para se tornarem 
leitores autônomos, no que se refere às diversas práticas de letramentos (DE OLIVEIRA; COSTA, 2017).

E, nessa perspectiva surge a necessidade de desenvolver os multiletramentos nas salas de aula, haja vista os novos formatos de comunicação que emergem nas sociedades pós-modernas, e especialmente a partir da evolução das Tecnologias Digitais de Informação e Comunicação (TDICs) (DE OLIVEIRA; COSTA, 2017).

Além disso, pesquisas sobre os multiletramentos buscam de forma recorrente uma junção com o campo de formação de professores e da pedagogia das línguas, sendo que considerações sobre o trabalho com textos multimodais/multissemióticos são um exemplo disso (VILLARTA-NEDER; FERREIRA, 2018).

A saber, em meados de 1996 surgiu o grupo de pesquisadores de Nova Londres - New London Group - (NLG), que reuniu estudiosos que se dedicaram a discussões profundas sobre os impactos que as tecnologias poderiam atingir nos espaços escolares (DE OLIVEIRA; COSTA, 2017).

Com isso, em um manifesto resultante de um Colóquio do GNL foi afirmada a necessidade de uma pedagogia dos multiletramentos, sendo que após uma semana de discussões foi publicado o manifesto A Pedagogy of Multiliteracies - Designing Social Futures (Uma pedagogia dos multiletramentos - desenhando futuros sociais) (ROJO; MOURA, 2012).

Dito isso, ao se falar em conceito de multiletramentos é necessário frisar que ele aponta para dois tipos específicos e importantes da multimodalidade, que estão presentes na sociedade contemporânea, a multiplicidade cultural e a semiótica/de liguagens (ROJO;MOURA, 2012).

Isto é, a multiplicidade cultural das populações ou multiplicidade de culturas, a qual se refere ao que se vê hoje em produções culturais letradas e que estão em circulação social (ROJO; MOURA, 2012).

E, em relação à multiplicidade semiótica/de linguagens, ela encontra-se presente nos textos em circulação social, sejam eles impressos, mídias audiovisuais ou não como animações, stop motions, machinemas, flanclipes, etc. (ROJO; MOURA, 2012).

Portanto, a multimodalidade ou multissemiose dos textos contemporâneos exigem multiletramentos, ou seja, textos compostos de várias 
linguagens/modos/semioses, os quais exigem capacidades e práticas para a sua compreensão e produção (ROJO; MOURA, 2012).

Nesse contexto, um texto multimodal é constituído por mais de um código semiótico como imagem, cores, caixa alta, gráficos, tabelas os quais interferem na produção de sentidos (FERREIRA, FERREIRA, 2017).

A saber, a presença de textos multissemióticos/multimodais nas mídias e nos ambientes digitais, requer dos professores um conhecimento que os capacite para lidar com eles (FRANCISCO; FERREIRA; GOULART, 2019).

E, os professores que não possuírem conhecimento para lidar com esses novos aspectos de linguagem presentes nas mídias digitais, deve buscar formação seja ela inicial ou continuada (FRANCISCO; FERREIRA; GOULART, 2019).

Portanto, um estudo que discuta sobre questões relacionadas aos encaminhamentos de práticas que considerem a análise de recursos semióticos se mostra relevante (VILLARTA-NEDER; FERREIRA, 2018).

Desta feita os cursos de formação de professores devem cumprir, cada qual na sua área, com exigências sociais para a formação de pessoas com capacidades de ler, produzir e escutar textos que integrem vários signos e as modalidades escrita e oral da semiose da língua (VILLARTA-NEDER; FERREIRA, 2018).

Sendo assim, as competências docentes em torno da leitura e da produção de gêneros semióticos, que estão presentes nos diversos espaços sociais, devem ser aperfeiçoadas em momentos de discussão que as favoreçam (VILLARTA-NEDER; FERREIRA, 2018).

A saber, isso contribuirá para uma formação docente que apresentará uma conformidade com as necessidades da sociedade da informação (VILLARTANEDER; FERREIRA, 2018).

Além disso, na contemporaneidade os profissionais do ensino são desafiados frente ao uso das tecnologias digitais no contexto educacional, uma vez que elas mudam a cada momento (ALMEIDA; FERREIRA, 2019).

Nesse sentido, o uso de recursos tecnológicos em sala de aula, demanda do professor que não está familiarizado com as tecnologias digitais, um processo de 
formação inicial que possibilite a ele aprender a utilizá-los em sala de aula (FRANCISCO; FERREIRA; GOULART, 2019).

Por isso, se torna premente uma formação de professores na utilização dos aparatos tecnológicos digitais afim de se promoverem mudanças nas formas de ensinar os alunos a ler e escrever diante das mudanças ocorridas nos suportes onde se exercita a leitura e a escrita (FRANCISO, FERREIRA, GOULART, 2019).

Portanto, o objetivo do presente estudo foi realizar uma revisão integrativa da literatura afim de discutir quais os encaminhamentos metodológicos/curriculares para o processo de formação de professores, envolvendo o trabalho com gêneros multissemióticos ou para o uso de tecnologias em sala de aula.

\section{MATERIAIS E MÉTODOS}

Foi feito um levantamento da literatura em agosto de 202I, nas bases de dados Periódicos CAPES e Google Acadêmico. Os descritores utilizados foram os seguintes: "formação de professores" AND "multissemiose" AND "tecnologias digitais da comunicação e informação" AND "teacher training" AND "multisemiosis" AND "digital communication and information technologies" em todas as bases de dados.

Desse modo, foram selecionados 08 artigos sendo incluídos segundo os critérios de elegibilidade conforme a Figura I. Os critérios de inclusão foram: artigos nos idiomas inglês, espanhol e português, nos últimos cinco anos, sobre os encaminhamentos para o processo de formação de professores, envolvendo o trabalho com gêneros multissemióticos ou para o uso de tecnologias em sala de aula. Os critérios de exclusão foram artigos de revisão de literatura. 
figura I. Fluxograma e critérios de seleção e inclusão dos trabalhos
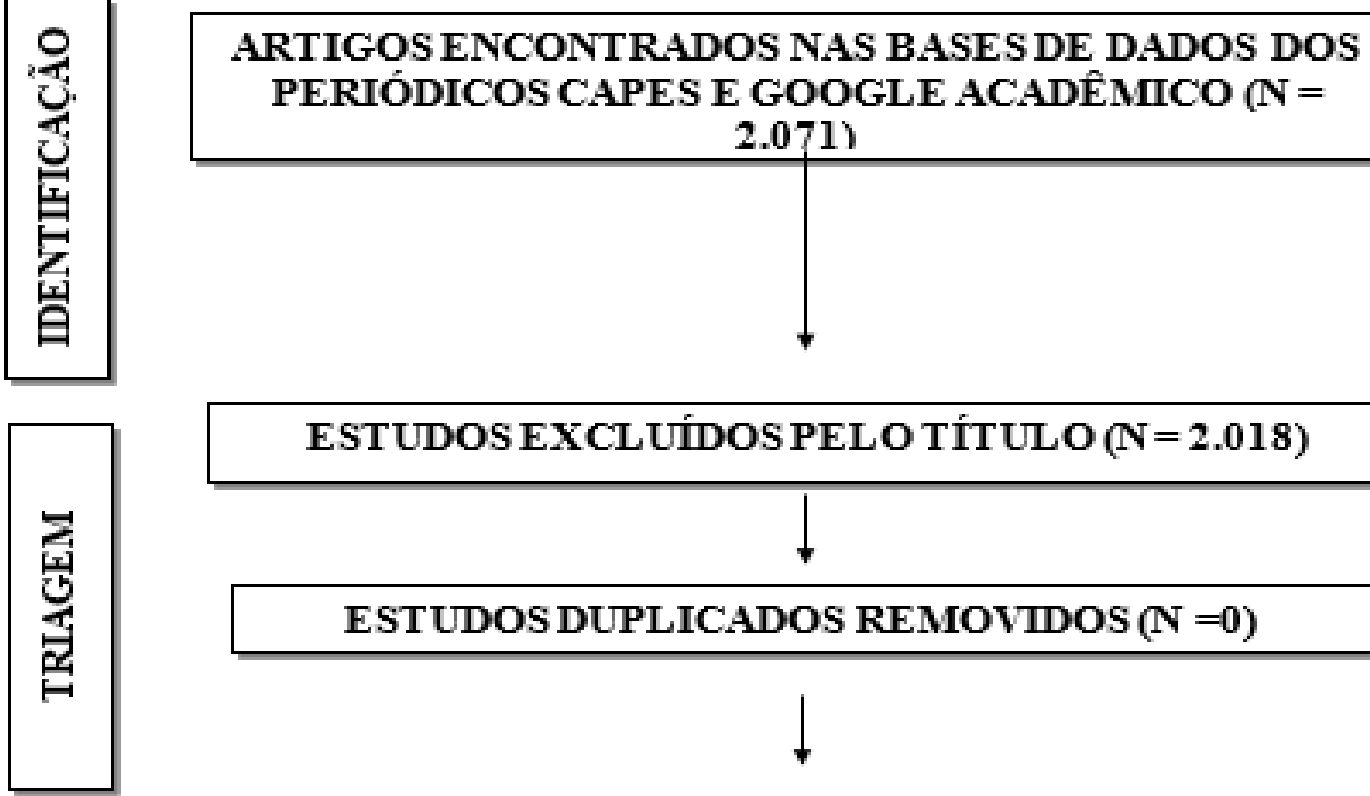

ESTUDOSEXCLÚíDOS PELO TÍTULO (N=2.018)
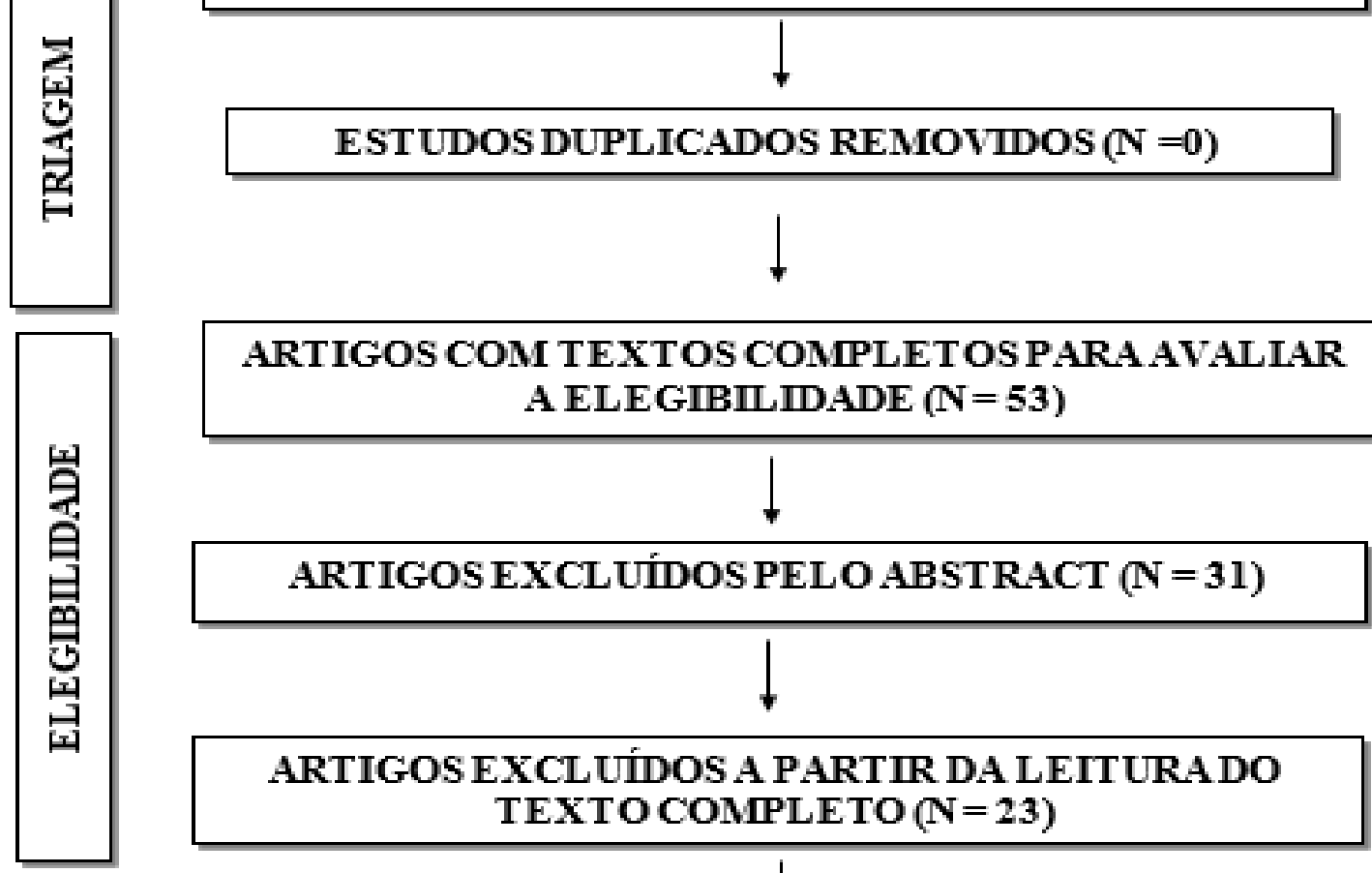

ARTIGOS COM TEXTOS COMPLETOS PARAAVALIAR

A ELEGIBILIDADE (N= 53)
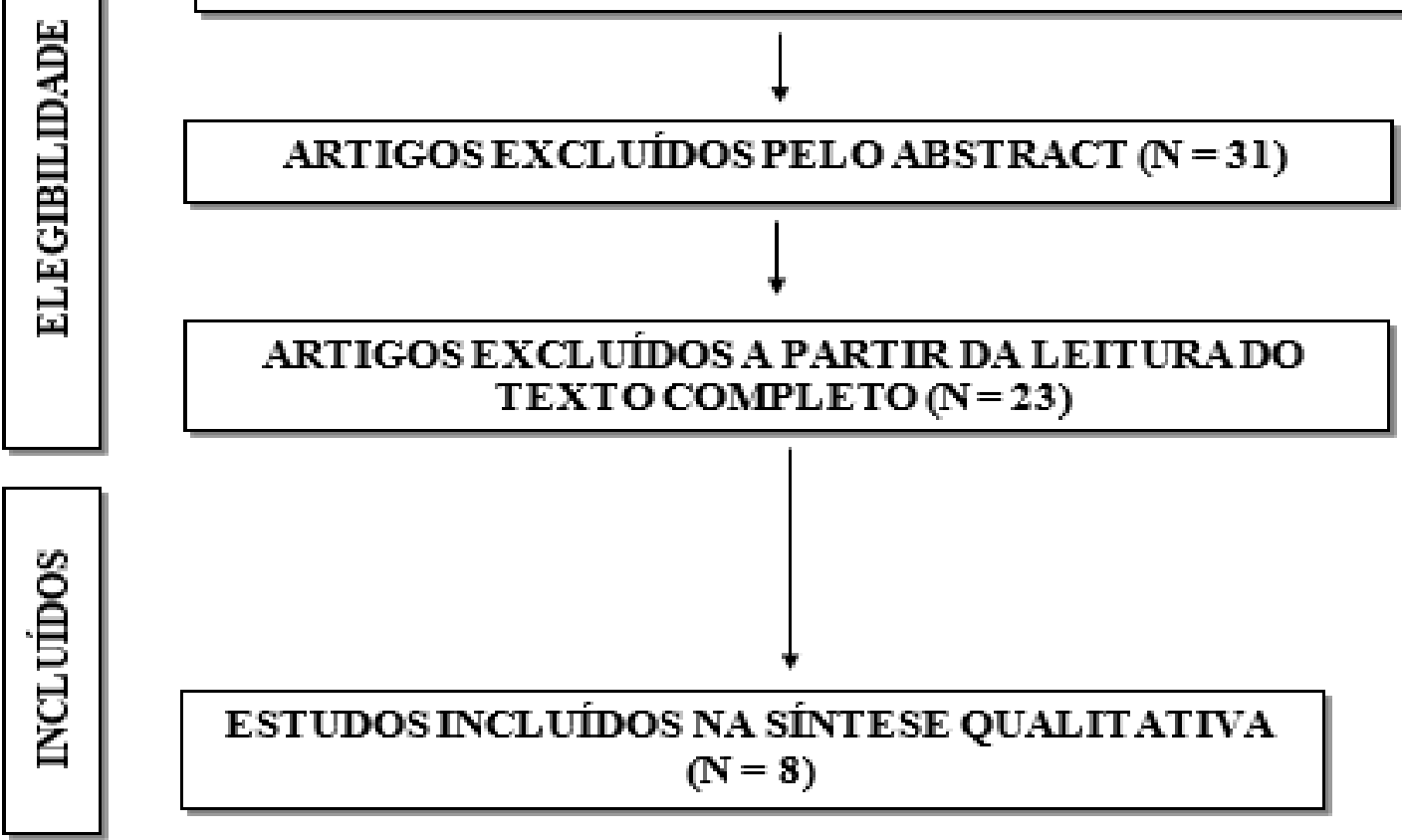

2. RESULTADOS

Os resultados do presente estudo encontram-se na Tabela I. 
Tabela I - Demonstrativo dos artigos que integram a Revisão Integrativa

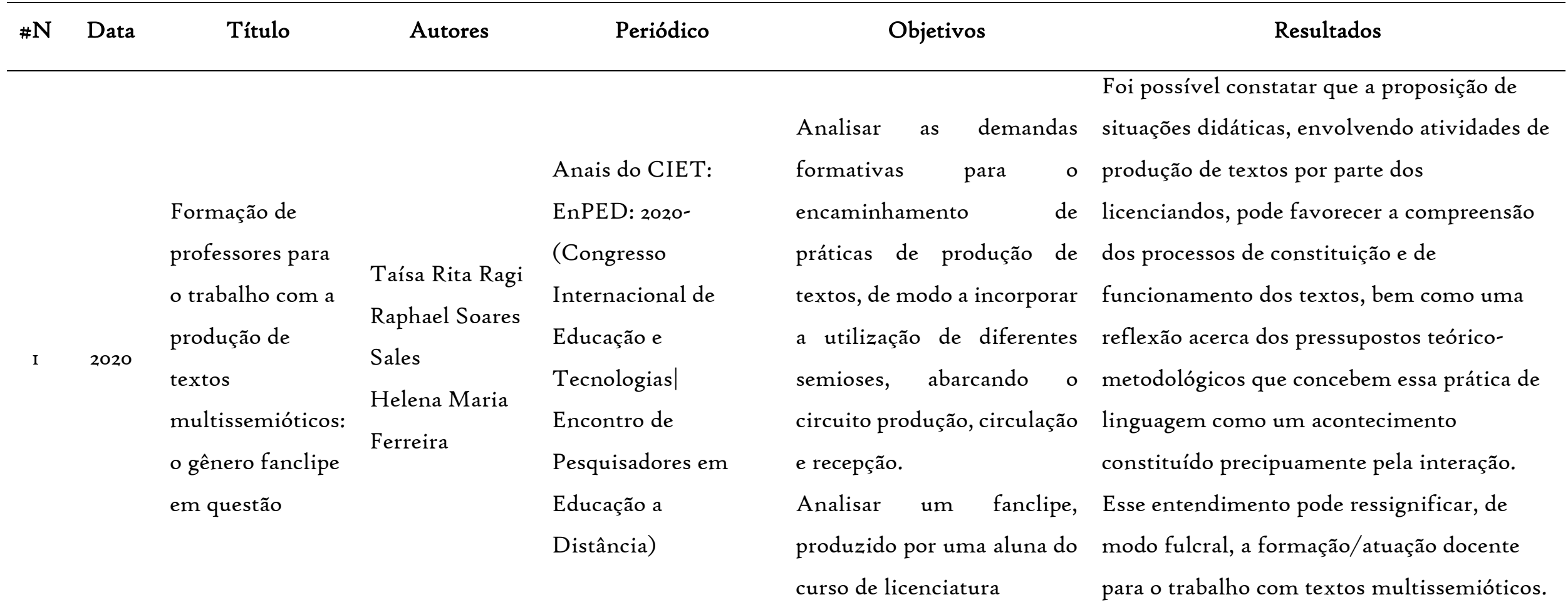




\begin{tabular}{|c|c|c|c|c|c|c|}
\hline$\# \mathrm{~N}$ & Data & Título & Autores & Periódico & Objetivos & Resultados \\
\hline 2 & 2019 & $\begin{array}{l}\text { Processos de } \\
\text { textualização em } \\
\text { textos não } \\
\text { verbais: } \\
\text { formando } \\
\text { professores na } \\
\text { perspectiva dos } \\
\text { multiletramentos }\end{array}$ & $\begin{array}{l}\text { Marco Antônio } \\
\text { Villarta-Neder } \\
\text { Helena Maria } \\
\text { Ferreira }\end{array}$ & Caleidoscópio & $\begin{array}{l}\text { Explorar algumas } \\
\text { possibilidades de análise do } \\
\text { processo de textualização da } \\
\text { videoanimação Vida Maria. }\end{array}$ & $\begin{array}{l}\text { Foi considerada importante uma dupla } \\
\text { abordagem quando se pensa nas práticas } \\
\text { escolares. A primeira delas é construir um } \\
\text { espaço de aprofundamento das questões que } \\
\text { uma textualização multissemiótica suscita e a } \\
\text { segunda abordagem refere-se ao ambiente da } \\
\text { sala de aula. Sem a disposição para ser } \\
\text { também e antes - espectador, e sem a } \\
\text { disposição para dialogar com outros } \\
\text { espectadores, que são seus alunos, o professor } \\
\text { dificilmente conseguirá desenvolver um } \\
\text { trabalho efetivo e interessante sobre qualquer } \\
\text { gênero, principalmente sobre aqueles que têm } \\
\text { uma marca mais característica da nossa } \\
\text { contemporaneidade. }\end{array}$ \\
\hline
\end{tabular}




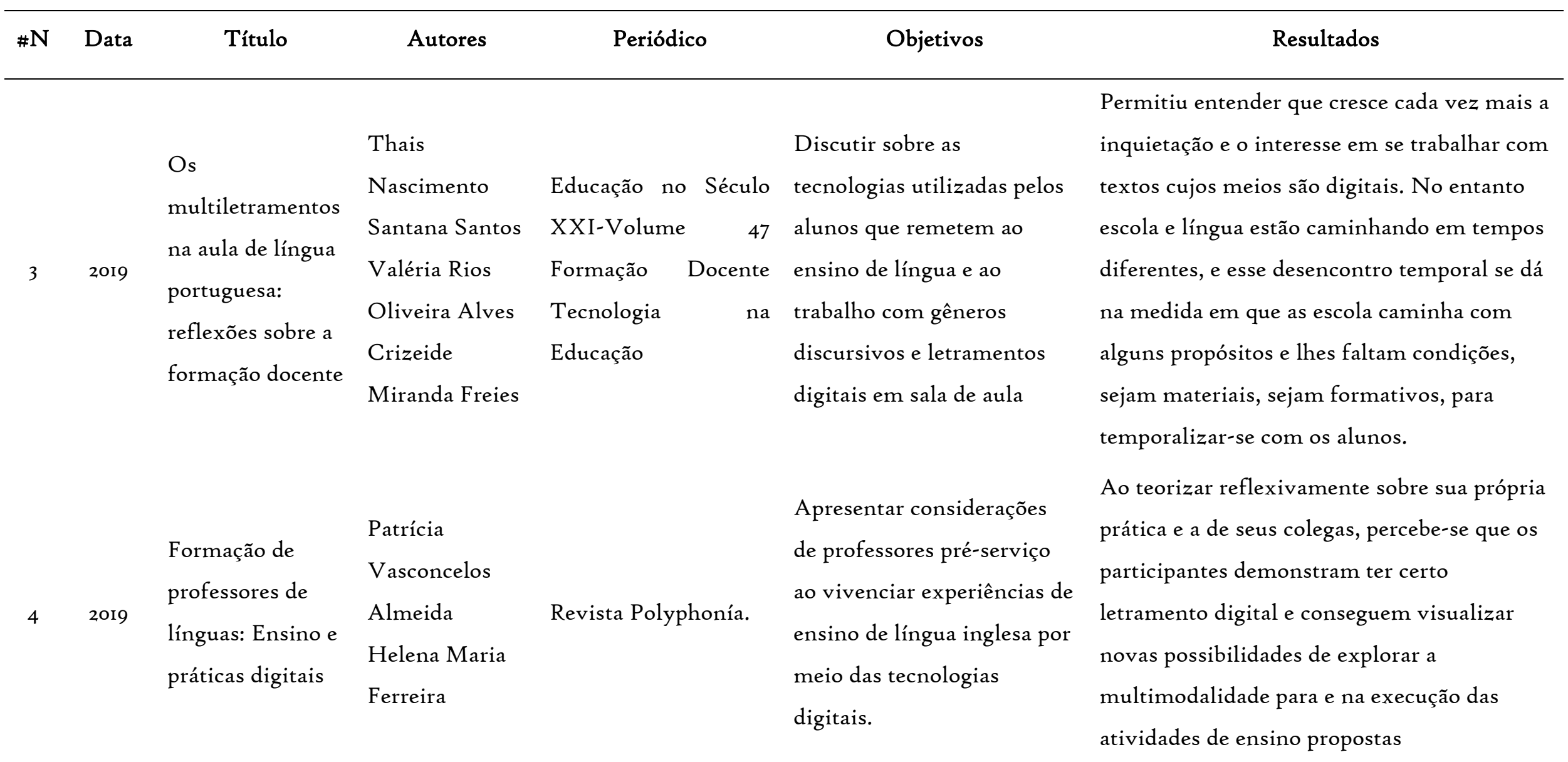




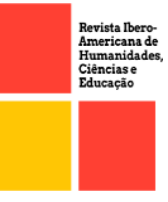

Revista Ibero- Americana de Humanidades, Ciências e Educação- REASE

open $\overbrace{\text { access }}$

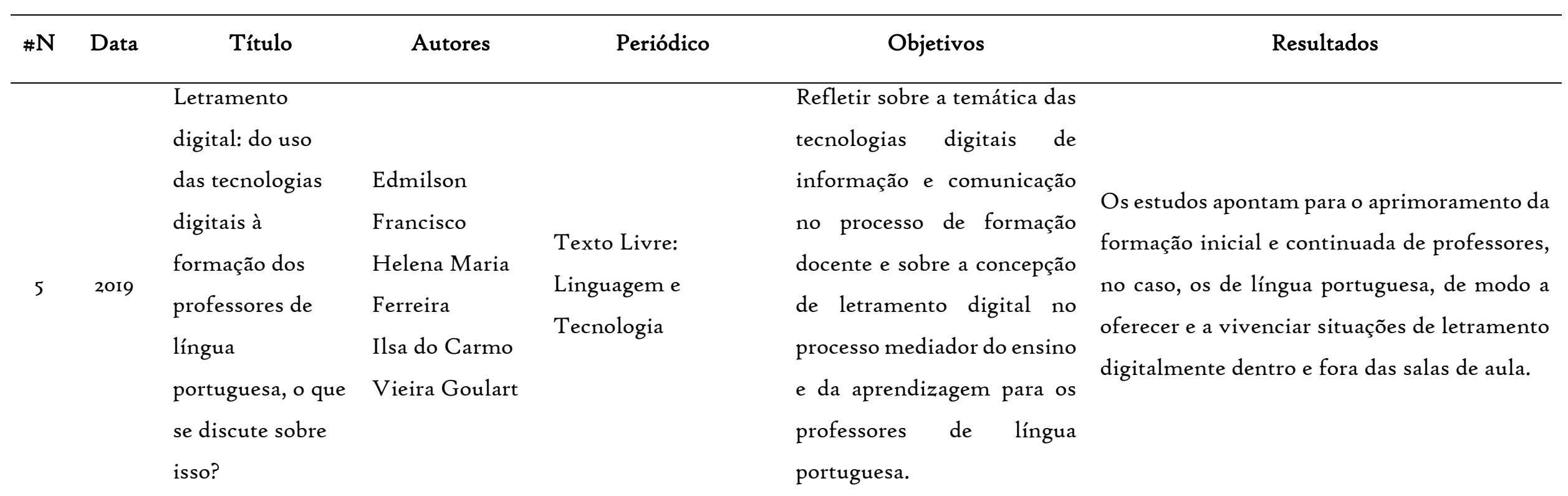




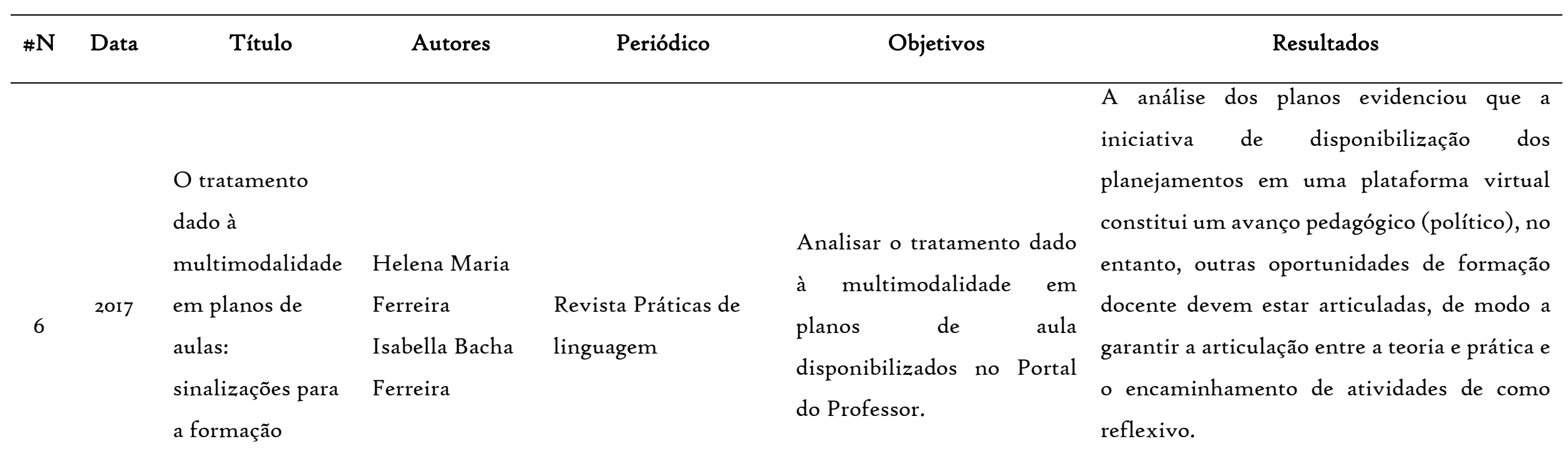

a formação

docente 


\begin{tabular}{|c|c|c|c|c|c|c|}
\hline$\# \mathrm{~N}$ & Data & Título & Autores & Periódico & Objetivos & Resultados \\
\hline 7 & 2017 & $\begin{array}{l}\text { Multiletramentos } \\
\text { e professores em } \\
\text { formação: um } \\
\text { olhar crítico para } \\
\text { o letramento } \\
\text { digital }\end{array}$ & $\begin{array}{l}\text { Luís Carlos de } \\
\text { Oliveira } \\
\text { Alessandra de } \\
\text { Oliveira Costa }\end{array}$ & $\begin{array}{l}\text { Revista Práticas de } \\
\text { linguagem }\end{array}$ & $\begin{array}{l}\text { Assimilar como a teoria dos } \\
\text { multiletramentos aponta } \\
\text { novas formas de promoção } \\
\text { do ensino de língua } \\
\text { portuguesa, especialmente } \\
\text { quando relacionadas ao } \\
\text { processo de formação inicial } \\
\text { de profissionais pedagogos. }\end{array}$ & $\begin{array}{l}\text { A partir dos resultados alcançados com a } \\
\text { pesquisa, observou-se a necessidade de os } \\
\text { cursos de graduação que buscam formar } \\
\text { professores revisarem suas matrizes } \\
\text { curriculares, a fim de complementarem o } \\
\text { tratamento referente aos letramentos que hoje } \\
\text { imperam fora da escola, às multilinguagens e } \\
\text { às diversas formas de ler, de produzir e } \\
\text { compartilhar criticamente os textos nos } \\
\text { espaços virtuais. }\end{array}$ \\
\hline
\end{tabular}




\begin{tabular}{|c|c|c|c|c|c|c|}
\hline$\# \mathrm{~N}$ & Data & Título & Autores & Periódico & Objetivos & Resultados \\
\hline 8 & 2017 & $\begin{array}{l}\text { Formação de } \\
\text { professores para } \\
\text { o trabalho com } \\
\text { textos } \\
\text { audiovisuais: } \\
\text { uma proposta de } \\
\text { leitura do gênero } \\
\text { videoanimação }\end{array}$ & $\begin{array}{l}\text { Helena Maria } \\
\text { Ferreira } \\
\text { Patrícia } \\
\text { Vasconcelos } \\
\text { Almeida }\end{array}$ & $\begin{array}{l}\text { Linguagem: Estudos e } \\
\text { Pesquisas }\end{array}$ & $\begin{array}{l}\text { Apresentar uma proposta de } \\
\text { leitura de uma } \\
\text { vídeoanimação e, por } \\
\text { consequência, uma análise } \\
\text { do referido gênero, tecendo } \\
\text { considerações para a sua } \\
\text { utilização em sala de aula. }\end{array}$ & $\begin{array}{l}\text { As possibilidades de análise apresentadas } \\
\text { comprovam a necessidade de se repensar a } \\
\text { formação docente para as questões } \\
\text { emergentes da inserção da tecnologia de } \\
\text { informação e comunicação como material } \\
\text { didático-pedagógico no cotidiano escolar bem } \\
\text { como a importância de se oferecer ao } \\
\text { professor, em seu percurso formativo, } \\
\text { subsídios para (re)pensar sua prática de } \\
\text { ensino da leitura. }\end{array}$ \\
\hline
\end{tabular}




\section{DISCUSSÃO}

O objetivo do presente estudo foi realizar uma revisão integrativa da literatura a fim de discutir quais são os encaminhamentos metodológicos/curriculares para o processo de formação de professores, envolvendo o trabalho com gêneros multissemióticos ou para o uso de tecnologias em sala de aula.

A saber, o professor desempenha um papel muito importante na sociedade em relação ao processo de ensino/aprendizagem e na preparação de cidadãos críticos, sendo, portanto, indispensável uma qualidade na mediação nas salas de aula (FRANCISCO, FERREIRA, GOULART, 2019).

Isso se deve ao fato de que, é pertinente inserir no alvo das discussões o que os alunos vivenciam a partir das interações por meio da internet, dado que alguns sequer desenvolveram um pensamento crítico sobre o que ouvem ou leem, afirmando como suas as afirmações de outras pessoas (FRANCISCO, FERREITA, GOULART, 2019).

Portanto, diante dos desafios enfrentados pelos professores no seu dia a dia, para que eles possam dominar um sentimento de incerteza e incapacidade, necessário se faz a busca por conhecimentos que os possibilitem realizar intervenções na realidade da sala de aula (FRANCISCO, FERREIRA, GOULART, 2019).

Desse modo, os professores devem buscar por uma constante formação, não podendo centrar suas práticas de ensino em determinada matéria e ignorando as novas configurações da sala de aula, as quais possuem alunos conectados à internet e fazendo uso de tecnologias digitais o tempo todo (FRANCISCO, FERREIRA, GOULART, 2019).

Espera-se que aos alunos seja propiciado um processo de ensino desenvolvido pelos professores que os capacite para enfrentar os desafios que se apresentam na sociedade (FRANCISO, FERREIRA, GOULART, 2019).

Além disso, a Base Comum Curricular (BNCC), espera dos estudantes que eles se apoderem das peculiaridades de cada linguagem, levando em consideração a visão global na qual elas estão inseridas (FRANCISCO, FERREIRA, GOULART, 2019).

E, que os alunos possam compreender que as linguagens não são estáticas e que todos estão envolvidos nesse processo de perene transformação e que de acordo com a 
BNCC seja garantido a eles um desenvolvimento de competências específicas (FRANCISCO, FERREIRA, GOULART, 2019).

Um exemplo disso é, que os alunos devem desenvolver competências para compreender e utilizar as tecnologias digitais da informação e comunicação, e que isso se dê de forma crítica, reflexiva, significativa e ética nas suas práticas sociais, inclusive escolares (FRANCISCO, FERREIRA, GOULART, 2019).

Desse modo, necessário refletir sobre como os professores, em especial os de língua portuguesa, podem reconfigurar as suas práticas pedagógicas através do uso das tecnologias digitais (FRANCISCO, FERREIRA, GOULART, 2019).

E, que essa reconfiguração acompanhe a nova ordem global de modo a possibilitar uma formação no panorama dos multiletramentos, preparando os alunos para o uso dos aparatos digitais e da produção e recepção crítica dos textos que estão presentes nos círculos sociais (FRANCISCO, FERREIRA, GOULART, 2019).

A saber, o imediatismo cultural que move muitas pessoas, as coloca em contato com mídias as quais estão configuradas em linguagem digital, tais como smartfones, tablets, aplicativos (FRANCISCO, FERREIRA, GOULART, 2019).

E, referidos dispositivos ao se conectarem a internet produzem diversos textos, a partir da troca de mensagens, redes sociais, e se organizam como práticas sociais de leituras e escritas integradas ao cotidiano, modificando a forma como as pessoas leem, escrevem e lidam com a informação (FRANCISCO, FERREIRA, GOUART, 2019).

Além disso, o contato com esses dispositivos e ambientes digitais, exige de seus usuários que eles desenvolvam novas habilidades de leitura, escrita e conhecimentos básicos de uso do aparato tecnológico a ser usado (FRANCISCO, FERREIRA, GOULART, 2019).

Não é só isso, hoje os textos têm possibilidade de serem criados com características diferentes da forma de como eram produzidos em material impresso, dado que exploram a multimodalidade e hipertextualidade (FRANCISCO, FERREIRA, GOULART, 2019).

Nesse sentido, os textos contemporâneos são constituídos por muitas semioses, e exigem do leitor capacidades e práticas para a compreensão de cada uma delas, ou seja, exigem os multiletramentos (ROJO; MOURA, 2012). 
E, Rojo e Moura (2012) ainda destacam que esses novos textos requerem novos letramentos, dado o seu caráter hiper (hipertextos, hipermídias, sendo que, o desafio que se coloca aos leitores não são as características dos novos textos multimodais, multissemióticos e hiper midiáticos.

Sendo que, caso assim fosse, os nativos digitais não teriam o prazer e a facilidade que possuem ao navegar na internet, o desafio está nas práticas de leitura e escrita escolares, as quais já não eram suficientes e restritas quando ainda se trabalhava com a "era do impresso"(ROJO;MOURA, 2012).

Rojo, Moura (2012), citando Lemke (2010), ressaltam que antes de se pensar em como disciplinar os multiletramentos é necessário pensar como os hábitos institucionais podem ser transformados com as tecnologias da informação.

Sendo assim, a presença de textos multissemióticos e multimodais tanto em mídias digitais como em ambientes, demandam dos professores de língua portuguesa que eles estejam preparados para trabalhar com textos que possuem tais características (FRANCISCO, FERREIRA, GOULART, 2019).

E, se os professores não possuem o conhecimento para lidar com referidos textos, se torna premente a busca por uma formação inicial ou continuada, tendo em vista a numerosa quantidade de textos com tais características que circulam nas mídias digitais (FRANCISCO, FERREIRA, GOULART, 2019).

Portanto, há necessidade de que os professores de língua portuguesa estejam preparados para o uso das tecnologias digitais, bem como saberem como os textos e as linguagens são e estão configurados nos espaços digitais (FRANCISCO, FERREIRA, GOULART, 2019).

Nesse sentido, os encaminhamentos didáticos-metodológicos a serem aderidos pelos professores devem se assentar nas suas referências as quais são advindas de suas experiências ou de seus saberes (VILLARTA-NEDER, FERREIRA, 2018).

Dessa forma, a formação docente envolve em seu processo pessoas e contextos e se assenta em um processo de reflexão o qual irá contribuir para diminuir problemas atrelados ao ensino de línguas (FERREIRA, ALEMIDA, 2018).

E, um desses problemas é a próprias complexidades da linguagem das produções multissemióticas que circulam socialmente e, portanto, assumem expressão 
pedagógica em função das necessidades escolares de um trabalho que circunde os diversos gêneros discursivos (FERREIRA, ALMEIDA, 2018).

A saber, a disseminação do acesso às tecnologias, fez com que a produção, a circulação e a recepção de gêneros textuais digitais assumissem proporções significativas nos convívios sociais (FERREIRA; ALMEIDA, 2018).

Diante disso, o atuar em sala de aula requer um trabalho mais estruturado com textos audiovisuais, o que acarreta um redimensionamento da formação docente, cabendo às instituições de ensino incluírem nas suas matrizes curriculares disciplinas que abordem o uso das TDIC's (FERREIRA; ALMEIDA, 2018).

Ferreira e Almeida (2017), ressaltam que o gênero vide animação merece destaque no aperfeiçoamento de habilidades multissemióticas pelos aprendizes e que ele possui complexidade composicional e temática.

Diante disso, referido gênero requer de seu leitor/expectador capacidades de compreensão das múltiplas semioses e de seus efeitos de sentido, o que traz uma exigência para a formação de professores (FERREIRA; ALMEIDA, 2018).

Isso se deve ao fato de que eles precisam usar das suas habilidades e competências de leitura diferenciadas para que compreendam os processos de textualização e rediscursividade dos textos audiovisuais (FERREIRA; ALMEIDA, 2018).

No entanto, mesmo sendo um gênero de destaque para o aperfeiçoamento das habilidades multissemióticas (FERREIRA, ALMEIDA, 2018), a discussão sobre a sua articulação e progressão de forma mais específica ainda está no início no campo educativo (VILLARTA-NEDER, FERREIRA, 2019).

Isso se deve ao fato de que, as práticas textuais ainda estão voltadas de forma predominante para o estudo de textos verbais escritos ou de gêneros como tiras de humor e charges, que possuem recursos semióticos de imagem estática (VILLARTANEDER; FERREIRA, 2018).

Desse modo, a discussão sobre novos gêneros multissemióticos deve ser incorporada no processo de formação de professores, ainda que isso seja uma tarefa complexa, diante de uma tradição que prioriza a modalidade verbal escrita (RAJI; SALLES; FERREIRA, 2020). 
Além disso, é necessário que sejam oportunizados espaços para a reflexão sobre a prática de produção de textos multissemióticos durante o percurso de formação dos professores, para que a eles seja possibilitado experiências de explorar as diversas semioses na construção do projeto de dizer (RAJI; SALLES; FERREIRA, 2020).

Não é só isso, no processo de formação do professor deve estar incluído o uso das tecnologias e demais aplicativos, diante de uma demanda que se torna cada vez mais urgente e necessária (RAJI; SALLES; FERREIRA, 2020).

Portanto, uma formação docente, seja ela inicial ou continuada deve se valer de conhecimentos que auxiliem o professor na construção de propostas de ensino que tenham discussões pelas vias tecnológicas e multiletradas (SANTOS; ALVES; FREIRE, 2019).

\section{CONCLUSÃO}

O objetivo do presente estudo foi realizar uma revisão integrativa da literatura a fim de discutir quais são os encaminhamentos metodológicos/curriculares para o processo de formação de professores, envolvendo o trabalho com gêneros multissemióticos ou para o uso de tecnologias em sala de aula.

A saber, a docência deve ser sempre refletida e repensada de forma crítica, seja para se adequar as demandas sociais e/ou por ser considerada uma construção social contínua.

Além disso, o cotidiano dos alunos fora do espaço escolar é dominado por atividades fundamentadas em atividades com gêneros textuais constituídos por linguagens multimodais/multissemióticas.

Não é só isso, a formação de professores deve contemplar uma preparação para o uso das tecnologias da informação e comunicação de forma crítica e reflexiva em sala de aula.

Desse modo, uma formação docente viável deve conceber ao docente que ele possa se valer de seus conhecimentos adquiridos durante a formação, a fim de que referidos conhecimentos o auxiliem na construção de propostas de ensino que perpassem pelas vias tecnológicas e multiletradas. 
Portanto, para que haja uma preparação de qualidade dos docentes é necessário que os cursos de formação de professores repensem suas matrizes curriculares a fim de incluir componentes para preparação dos futuros docentes para o uso das tecnologias e o trabalho envolvendo os gêneros multissemióticos em sala de aula.

\section{REFERÊNCIAS}

Almeida, Patricia Vasconcelos; Ferreira, Helena Maria. formação de professores de línguas: ensino e práticas digitais. revista polyphonía, v. 30, n. I, p. I02-II9, 2019.

de Oliveira, Luís Carlos; Costa, Alessandra De Oliveira. multiletramentos e professores em formação: um olhar crítico para o letramento digital. revista práticas de linguagem, p. I16-133, 2017.

dudeney, g.; hockly, n.; pegrum, m. letramentos digitais. trad. marcos Marcionilo. são Paulo: parábola editorial, 2016.

Ferreira, helena maria; almeida, patrícia Vasconcelos. formação de professores para o trabalho com textos audiovisuais: uma proposta de leitura do gênero vide animação. linguagem: estudos e pesquisas, v. 22, n. 2, 2018.

Ferreira, Helena Maria; Ferreira, Isabella Bacha. o tratamento dado à multimodalidade em planos de aulas: sinalizações para a formação docente. revista práticas de linguagem, p. 592-603, 2017.

Francisco, Edmilson; Ferreira, Helena Maria; Goulart, Ilsa Do Carmo Vieira. letramento digital: do uso das tecnologias digitais à formação dos professores de língua portuguesa, o que se discute sobre isso?. texto livre: linguagem e tecnologia, v. I2, n. 3, p. 109-127, 2019.

Ragi, Taísa Rita; Salles, Raphael Soares; Ferreira, Helena Maria. formação de professores para o trabalho com a produção de textos multissemióticos: o gênero fanclipe em questão. in: anais do ciet: enped: 2020-(congresso internacional de educação e tecnologias| encontro de pesquisadores em educação a distância). 2020. rojo, r.; moura, e. multiletramentos na escola. São Paulo: parábola, 2012. santos, Thais nascimento Santana; Alves, Valéria rios oliveira; freire, Crizeide Miranda. os multiletramentos na aula de língua portuguesa: reflexões sobre a formação 
docente. educação no século xxi-volume 47 formação docente tecnologia na educação, p. 66-70, 2019.

VILLARTA-NEDER, M. A.; FERREIRA, H. M. Processos de textualização em textos não verbais: formando professores na perspectiva dos multiletramentos. Calidoscópio, [S. 1.], v. I7, n. 3, p. 592-614, 2018. Disponível em: http://revistas.unisinos.br/index.php/calidoscopio/article/view/cld.2019.173.10.

Acesso em: 13 out. 2021. 